\title{
Italian guidelines for management and treatment of hyperbilirubinaemia of newborn infants $\geq$ 35 weeks' gestational age
}

\author{
Costantino Romagnoli ${ }^{*}$, Giovanni Barone ${ }^{1}$, Simone Pratesi ${ }^{2}$, Francesco Raimondi ${ }^{3}$, Letizia Capasso ${ }^{3}$, Enrico Zecca ${ }^{1}$, \\ and Carlo Dani ${ }^{2}$ on behalf of the Task Force for hyperbilirubinaemia of the Italian Society of Neonatology
}

\begin{abstract}
Hyperbilirubinaemia is one of the most frequent problems in otherwise healthy newborn infants. Early discharge of the healthy newborn infants, particularly those in whom breastfeeding is not fully established, may be associated with delayed diagnosis of significant hyperbilirubinaemia that has the potential for causing severe neurological impairments. We present the shared Italian guidelines for management and treatment of jaundice established by the Task Force on hyperbilirubinaemia of the Italian Society of Neonatology.

The overall aim of the present guidelines is to provide an useful tool for neonatologists and family paediatricians for managing hyperbilirubinaemia.
\end{abstract}

Keywords: Hyperbilirubinaemia, Jaundice, Newborn, Discharge, Guidelines

\section{Background}

Hyperbilirubinaemia is a very common condition. The prevention, detection and management of jaundice remains a challenge especially because of early discharge of healthy late preterm and full term newborn infants [1-3]. Early discharge of the healthy newborn, particularly those in whom breastfeeding is not fully established, may be associated with delayed diagnosis of severe hyperbilirubinaemia $[1,4,5]$. A recent survey performed by Dani et al. [6] showed that the management of hyperbilirubinaemia is not homogeneous in Italy. Therefore the Task Force on hyperbilirubinaemia of the Italian Society of Neonatology drew up national guidelines for management of jaundice in the newborn and established a national registry of kernicterus and hyperbilirubinaemia in order to monitor the incidence of cases of kernicterus and severe hyperbilirubinaemia in Italy over time.

\section{Focus of guidelines}

The overall aim of this guidelines is to provide an useful tool for neonatologists and family paediatricians for

\footnotetext{
* Correspondence: cromagnoli@rm.unicatt.it

${ }^{1}$ Division of Neonatology, Department of Pediatrics, Catholic University S H, Largo A. Gemelli, 8, Rome 00168, Italy

Full list of author information is available at the end of the article
}

managing hyperbilirubinaemia. These recommendations promote an approach based on the importance of universal systematic assessment for the risk of severe hyperbilirubinaemia, close follow-up, and prompt intervention when indicated. The statement fully applies to the care of infants at 35 or more weeks of gestation, while only some recommendations could be used for newborn infants with lower gestational age (GA).

\section{Methods of statement development}

Literature searches were last updated in September 2013. Guidelines from AAP [7-9], NICE [10,11], Canadian Pediatric Association [12], Nederland Neonatal Research Network [13], Norwegian Pediatric Society [14], Israel [15], New Zealand [16], Australia (Queensland) [17], India [18], Spain [19], Switzerland [20] were considered. Studies conducted in the neonatal units of Lazio were also evaluated to obtain recommendations more suitable for Italian population [21-23].

The hierarchy of evidence from the Centre for Evidence-Based-Medicine was applied (see Table 1) [24].

\section{Acute bilirubin encephalopathy}

The main aim of these guidelines is to avoid cases of acute bilirubin encephalopathy (ABE) by establishing levels of 
Table 1 The hierarchy of evidence from the centre for evidence-based-medicine

\begin{tabular}{ll}
\hline Level & Definition \\
\hline $1 a$ & Systematic review (with homogeneity) of RCTs \\
$1 b$ & Individual RCT (with narrow confidence interval) \\
$2 a$ & Systematic review (with homogeneity) of cohort studies \\
$2 b$ & Individual cohort study \\
$3 a$ & Systematic review (with homogeneity) of case-control studies \\
$3 b$ & Individual case-control study \\
4 & Case-series (and poor quality cohort and case-control studies) \\
5 & Expert opinion without explicit critical appraisal, or \\
& based on physiology, bench research or "first principles" \\
\hline
\end{tabular}

serum bilirubin at risk of neurologic damage. A total serum bilirubin (TSB) of $20 \mathrm{mg} / \mathrm{dl}$ should not be exceeded in the first 96 hours of life in term newborns. After 96 hours of life a TSB of $25 \mathrm{mg} / \mathrm{dl}$ should be avoided (evidence level $2 b)$, since the efficacy of Blood-brain-Barrier increases with postnatal age. The safe bilirubin level is lower for preterm infants: $12 \mathrm{mg} / \mathrm{dl}$ for babies with $\mathrm{GA} \leq 30$ weeks and $15 \mathrm{mg} / \mathrm{dL}$ for babies with GA 31-36 weeks [25,26].

Apart from TSB level, gestational age and postnatal age, some more risk factors for $\mathrm{ABE}$ should also be considered:

- Birth asphyxia

- Severe hypothermia (Tc $<36^{\circ} \mathrm{C}$ for $>6$ hours)

- Respiratory failure (RDS, pneumonia, meconium aspiration syndrome)

- Prolonged acidosis ( $\mathrm{pH}<7.20$ for $>6$ hours)

- Severe hypoglycaemia (glucose $<45 \mathrm{mg} / \mathrm{dl}$ for $>$ 12 hours)

- Severe haemolysis

- Sepsis and meningitis

- Drugs impairing bilirubin/albumin binding

\section{Bilirubin measurement}

All infants should be routinely monitored for the development of jaundice. The ability of physicians and other health care providers to recognise clinically significant jaundice and predict bilirubin levels based on the coephalo-caudal progression of jaundice is limited (evidence level 1b) [27-31].

Therefore each jaundiced newborn should receive a bilirubin measurement. Transcutaneous bilirubin (TcB) can be used as first step in order to reduce the number of invasive and painful blood sampling. BiliCheck TM (Respironics, Marietta, GA - USA) and JM-103 (Drager Medical Inc, Telford, Pennsylvania) are the two most used bilirubinometers in the studies conducted in the Italian population and both had good correlation with TSB values $[21,22,32,33]$. TSB measurement is always necessary when the level of bilirubin is high and for therapeutic decisions (evidence level 1b).

\section{Prediction of hyperbilirubinaemia}

The evaluation of jaundice is now facilitated by the availability of different nomograms for both serum [34] and transcutaneous bilirubin $[21,35,36]$. However, a nomogram could not perform well in one specific setting if the racial, genetic and environmental background of that setting are too different from that of the reference population. Furthermore, predictive tools should be developed in one sample and validated in another one. Hour-specific percentile based nomograms have been developed in cohorts of healthy Italian full term neonates or Italian neonates with $\geq 35$ weeks' gestational age using serial measurements of TcB and TSB (Tables 2 and 3; Figures 1 and 2) [21,23]. In a second phase the predictive ability of these nomograms has been evaluated. Sensitivity, specificity, positive and negative predictive value of percentiles in predicting significant hyperbilirubinaemia (defined as TSB $>17 \mathrm{mg} / \mathrm{dL}$ or need for phototherapy) are listed in Tables 4 and 5 .

On the base of these studies the Task Force on hyperbilirubinaemia of the Italian Society of Neonatology

Table 2 Values of TcB corresponding at the 50th and 75th percentile of the hour-specific nomogram

\begin{tabular}{|c|c|c|c|c|c|c|c|c|}
\hline$h$ & 50th & 75th & $\mathrm{h}$ & 50th & 75th & h & 50th & 75th \\
\hline 24 & 6,3 & 7,8 & 49 & 7,7 & 10,4 & 73 & 10 & 11,7 \\
\hline 25 & 6,3 & 7,8 & 50 & 7,8 & 10,4 & 74 & 10 & 11,8 \\
\hline 26 & 6,4 & 7,8 & 51 & 8 & 10,5 & 75 & 10,1 & 11,9 \\
\hline 27 & 6,4 & 7,9 & 52 & 8,1 & 10,5 & 76 & 10,1 & 11,9 \\
\hline 28 & 6,4 & 7,9 & 53 & 8,3 & 10,6 & 77 & 10,2 & 12 \\
\hline 29 & 6,5 & 7,9 & 54 & 8,4 & 10,6 & 78 & 10,2 & 12,1 \\
\hline 30 & 6,5 & 7,9 & 55 & 8,6 & 10,7 & 79 & 10,3 & 12,2 \\
\hline 31 & 6,6 & 8,1 & 56 & 8,7 & 10,8 & 80 & 10,4 & 12,2 \\
\hline 32 & 6,6 & 8,4 & 57 & 8,9 & 11 & 81 & 10,5 & 12,3 \\
\hline 33 & 6,7 & 8,6 & 58 & 9 & 11,1 & 82 & 10,5 & 12,3 \\
\hline 34 & 6,7 & 8,8 & 59 & 9,2 & 11,2 & 83 & 10,6 & 12,4 \\
\hline 35 & 6,8 & 9,1 & 60 & 9,3 & 11,3 & 84 & 10,7 & 12,4 \\
\hline 36 & 6,8 & 9,3 & 61 & 9,4 & 11,3 & 85 & 10,7 & 12,4 \\
\hline 37 & 6,9 & 9,4 & 62 & 9,5 & 11,4 & 86 & 10,8 & 12,4 \\
\hline 38 & 7,1 & 9,5 & 63 & 9,6 & 11,4 & 87 & 10,8 & 12,4 \\
\hline 39 & 7,2 & 9,7 & 64 & 9,6 & 11,4 & 88 & 10,8 & 12,4 \\
\hline 40 & 7,3 & 9,8 & 65 & 9,7 & 11,5 & 89 & 10,9 & 12,4 \\
\hline 41 & 7,5 & 9,9 & 66 & 9,8 & 11,5 & 90 & 10,9 & 12,4 \\
\hline 42 & 7,5 & 10 & 67 & 9,8 & 11,5 & 91 & 10,9 & 12,5 \\
\hline 43 & 7,5 & 10,1 & 68 & 9,8 & 11,5 & 92 & 10,9 & 12,5 \\
\hline 44 & 7,6 & 10,1 & 69 & 9,9 & 11,6 & 93 & 10,9 & 12,6 \\
\hline 45 & 7,6 & 10,2 & 70 & 9,9 & 11,6 & 94 & 10,9 & 12,6 \\
\hline 46 & 7,6 & 10,2 & 71 & 9,9 & 11,6 & 95 & 10,9 & 12,7 \\
\hline 47 & 7,6 & 10,3 & 72 & 9,9 & 11,6 & 96 & 10,9 & 12,7 \\
\hline 48 & 7,6 & 10,3 & & & & & & \\
\hline
\end{tabular}


Table 3 Values of TSB corresponding at the 50th, 75th and 90th percentile of the hour-specific nomogram

\begin{tabular}{|c|c|c|c|c|c|c|c|c|c|c|c|}
\hline & Utn & 75th & 90th & $h$ & th & 75th & 90th & $h$ & 50th & 75th & 90 \\
\hline & 6.1 & 7.5 & 8.9 & 19 & 9.0 & 10.3 & 11.9 & 73 & 10.0 & 11.7 & 13.2 \\
\hline & & & & 50 & & & & 74 & & & \\
\hline & 6 & 7.8 & & 51 & & .4 & & 75 & & & \\
\hline & 6.5 & 8.0 & 9.3 & 52 & & 105 & 127 & 76 & & & \\
\hline & & & & 53 & & & & 77 & & & \\
\hline & 6.8 & 8.3 & 9.6 & 54 & 9.3 & 10.7 & 12.4 & 7 & 2 & 9 & 13.5 \\
\hline & 7.0 & 8.5 & & 35 & & 10.0 & 12.5 & 1 & & & \\
\hline & 7.2 & 8.6 & 9.9 & 56 & 93 & 108 & 12.5 & 80 & 10.3 & 12.1 & 13.6 \\
\hline & 7.3 & & & 5 & & & 12.0 & 81 & & & \\
\hline & I & & & 58 & & & & 82 & & & \\
\hline & 7.7 & 9.0 & & 5 & .4 & 110 & 12.8 & 83 & 10.6 & 12.3 & \\
\hline & 7. & & & 60 & 9.5 & 11.0 & 9 & 84 & 6 & 12.4 & \\
\hline & 8.0 & 9.2 & 10.8 & 61 & & 11.1 & 12.9 & 85 & 10.6 & & 13.9 \\
\hline & 8.1 & & & 62 & & & 12.9 & 86 & & & \\
\hline & 8.2 & 9.4 & 10.9 & 63 & 95 & 112 & 12.9 & 87 & 1 & 12.5 & \\
\hline 39 & 8.3 & 9.5 & & 64 & & & & 88 & & & \\
\hline 10 & 84 & 9.6 & 1 & 65 & 9.6 & 11.3 & 13.0 & 89 & 10.8 & & \\
\hline & 8.5 & 9.7 & & 66 & 9.6 & & & 90 & 10 & & \\
\hline & 8.6 & 9.8 & 11.1 & 67 & 6 & 11.4 & 13.0 & 91 & 10.9 & 12.7 & 12 \\
\hline & 8.7 & & & 68 & & & 13.1 & 92 & & & \\
\hline 44 & 8.7 & 9.5 & I & 69 & 9.7 & & 0.1 & 9. & & & 14.7 \\
\hline 45 & 8.8 & 10.0 & 11.5 & 70 & 9.8 & 116 & 13.1 & 94 & 11.3 & $1=$ & 14.8 \\
\hline 40 & 8.9 & 1 & 11.6 & 71 & 9.0 & 11.7 & 13.2 & 95 & .4 & 13.4 & 1 \\
\hline $1+$ & 8.9 & 10.2 & 11.7 & 72 & 9.9 & 17 & 3.2 & 96 & .5 & 13.5 & 15.0 \\
\hline & .0 & 0.2 & 1100 & & & & & & & & \\
\hline
\end{tabular}

drew up the following recommendations for infants with $\mathrm{GA} \geq 35$ weeks (evidence level $1 \mathrm{~b}$ ).

\section{Recommendations:}

- All jaundiced newborn infants should be tested with a TcB measurement and the value should be plotted on the hour-specific nomogram for TcB measurements (Table 2).

- If the TcB measurement is $>75$ th percentile, a serum determination of bilirubin should be performed and the value should be plotted on the nomogram for TSB measurements (Table 3).

- Newborn infants with a TSB value $<50$ th percentile in the first 48 hours of live and babies with a value $<75$ th percentile after 48 hours of life are not at risk of hyperbilirubinaemia and do not require further evaluations.

- Newborn infants with a TSB value $>50$ th percentile in the first 48 hours of live and babies with a value $>$ 75th percentile after 48 hours of life are at risk of hyperbilirubinaemia and should be tested again after 24 or 48 hours according to the hours of life and the presence of clinical risk factors.

At present, there are no nomograms able to predict hyperbilirubinaemia in infants with GA $<35$ weeks. Therefore bilirubin measurements should be decided according to GA and treatment thresholds (evidence level 5).

\section{Treatment: phototherapy}

There is no reliable evidence to inform the choice of thresholds for starting phototherapy. For this reasons guidelines report different recommendations. In determining the

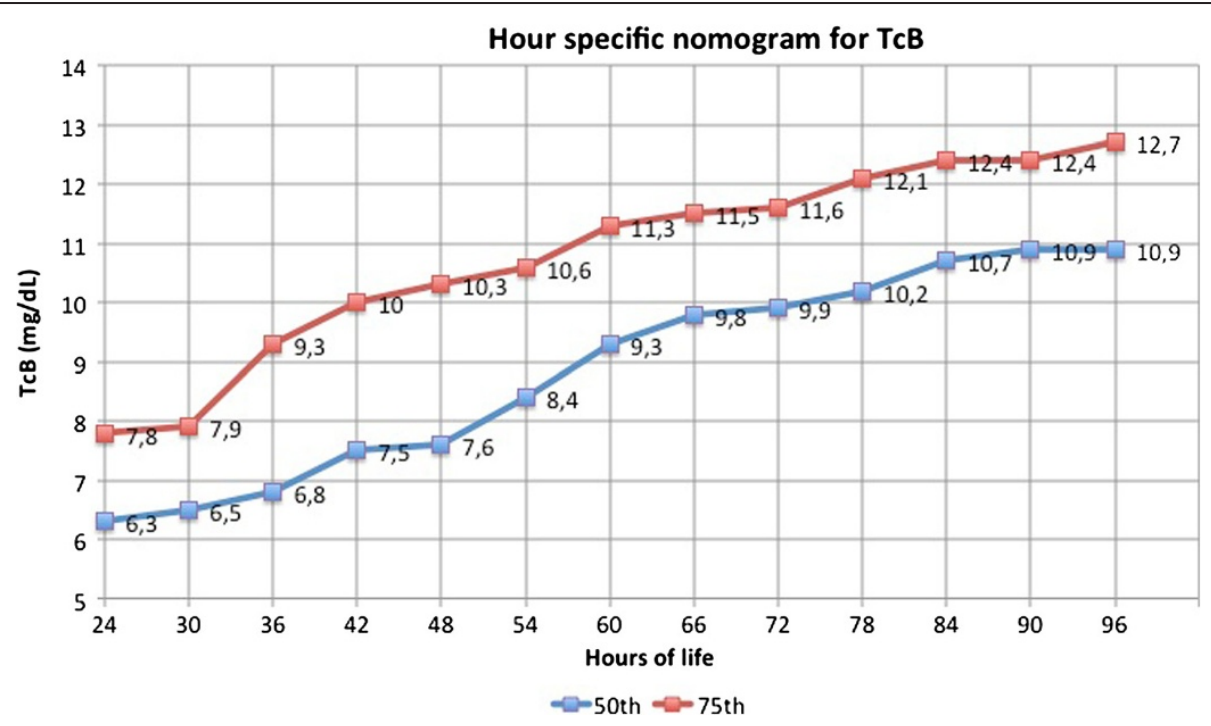

Figure 1 Depicts hour-specific percentile based nomograms for TcB. 


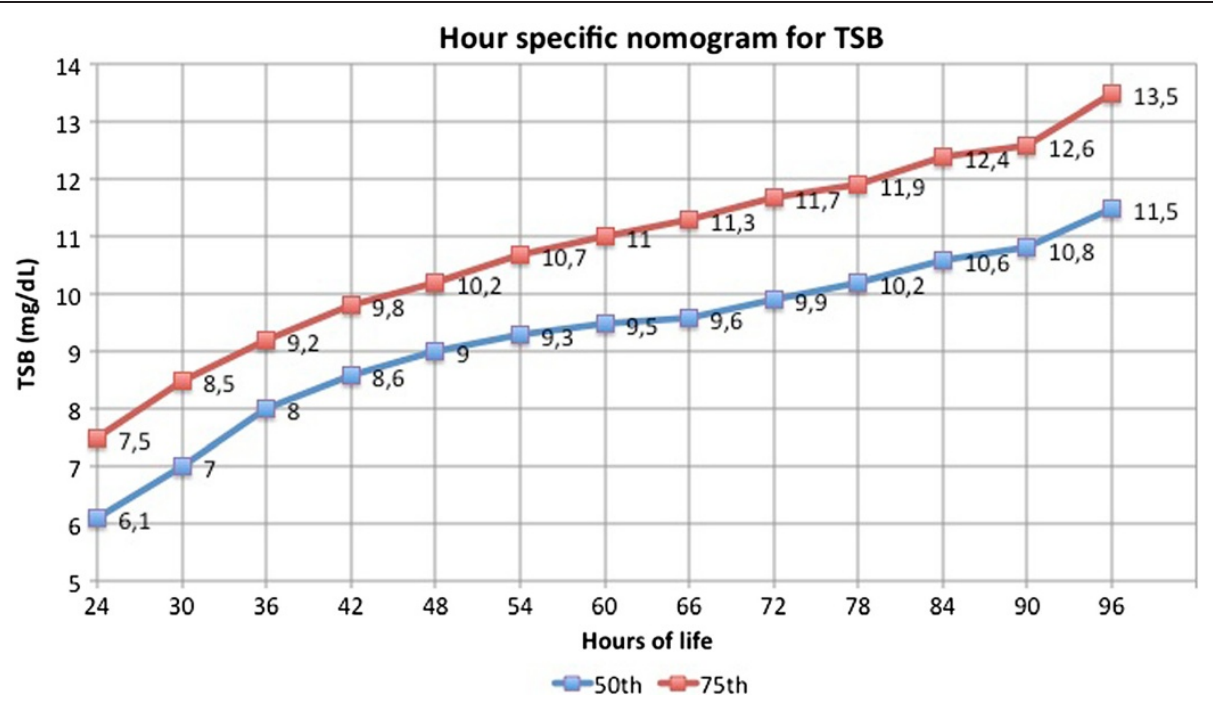

Figure 2 Depicts hour-specific percentile based nomograms for TSB.

bilirubin thresholds for treatment, the Italian Society of Neonatology considered as primary aim to choose a threshold allowing a large margin of safety, being the threshold for starting phototherapy less than that for performing exchange transfusion, and not so low to become unnecessary.

The thresholds for phototherapy are showed in a graph in which total bilirubin is plotted against age in hours. The groups of GA (GA < 30; 30-31; 32-34; 35-37; > 37) are represented by different lines (Figure 3 ).

\section{Recommendations:}

- Phototherapy should be administered for irradiating the most of the infant's skin.
- Intensive phototherapy with an irradiance $>35 \mu \mathrm{W} /$ $\mathrm{cm}^{2} / \mathrm{nm}$ is recommended. Daylight, blue light, conventional or blue LED phototherapy can be used (evidence level 1a).

- Fiberoptic phototherapy can be used even if it is less effective than conventional phototherapy and require more prolonged treatment (evidence level 1a) [37].

- Serum bilirubin should be tested 4-8 hours after the beginning of phototherapy or earlier if TSB $<3 \mathrm{mg} / \mathrm{dL}$ less than threshold for exchange transfusion.

Subsequently, TSB should be assessed every 1224 hours to monitor the treatment effectiveness.

- In case of treatment failure, multiple phototherapy should be started adding a fiberoptic device to the

Table 4 Ability of TCB measurements over the 50th, the 75th and the 90th percentile of TcB nomogram to predict significant hyperbilirubinaemia, for designated time periods

\begin{tabular}{|c|c|c|c|c|c|c|c|c|}
\hline Hours of life & TP & $\mathrm{FN}$ & $\mathrm{TN}$ & FP & Sensitivity & Specificity & PPV & NPV \\
\hline \multicolumn{9}{|l|}{$24-48$ hours } \\
\hline$<50$ th percent & 27 & 0 & 161 & 460 & $100 \%$ & $25.9 \%$ & $5.5 \%$ & $100 \%$ \\
\hline$<75$ th percent & 25 & 2 & 429 & 192 & $92.6 \%$ & $69.1 \%$ & $11.5 \%$ & $99.5 \%$ \\
\hline$<90$ th percent & 14 & 13 & 564 & 57 & $51.9 \%$ & $90.8 \%$ & $19.7 \%$ & $97.7 \%$ \\
\hline \multicolumn{9}{|l|}{$49-72$ hours } \\
\hline$<50$ th percent & 21 & 0 & 410 & 615 & $100 \%$ & $40 \%$ & $3.3 \%$ & $100 \%$ \\
\hline$<75$ th percent & 21 & 0 & 702 & 323 & $100 \%$ & $68.5 \%$ & $6.1 \%$ & $100 \%$ \\
\hline$<90$ th percent & 18 & 3 & 888 & 137 & $85.7 \%$ & 86.6 & $11.6 \%$ & $99.7 \%$ \\
\hline \multicolumn{9}{|l|}{73 - 96 hours } \\
\hline$<50$ th percent & 7 & 0 & 246 & 220 & $100 \%$ & $52.8 \%$ & $3.1 \%$ & $100 \%$ \\
\hline$<75$ th percent & 7 & 0 & 348 & 118 & $100 \%$ & $74.7 \%$ & $5.6 \%$ & $100 \%$ \\
\hline$<90$ th percent & 5 & 2 & 409 & 57 & $71.4 \%$ & $87.8 \%$ & $8.1 \%$ & $99.5 \%$ \\
\hline
\end{tabular}


Table 5 Ability of TSB measurements over the 50th, the 75th and the 90th percentile of TSB nomogram to predict significant hyperbilirubinaemia, for designated time periods

\begin{tabular}{|c|c|c|c|c|c|c|c|c|}
\hline Hours of life & TP & $\mathrm{FN}$ & $\mathrm{TN}$ & FP & Sensitivity & Specificity & PPV & NPV \\
\hline \multicolumn{9}{|l|}{$24-48$ hours } \\
\hline$<50$ th percent & 24 & 1 & 357 & 263 & $96.0 \%$ & $57.6 \%$ & $8.4 \%$ & $99.7 \%$ \\
\hline$<75$ th percent & 22 & 3 & 479 & 141 & $88.0 \%$ & $77.3 \%$ & $13.5 \%$ & $99.4 \%$ \\
\hline$<90$ th percent & 12 & 13 & 576 & 44 & $48.0 \%$ & $92.9 \%$ & $21.4 \%$ & $97.8 \%$ \\
\hline \multicolumn{9}{|l|}{$49-72$ hours } \\
\hline$<50$ th percent & 23 & 0 & 657 & 368 & $100 \%$ & $64.1 \%$ & $5.9 \%$ & $100 \%$ \\
\hline$<75$ th percent & 22 & 1 & 860 & 165 & $95.7 \%$ & $83.9 \%$ & $11.8 \%$ & $99.9 \%$ \\
\hline$<90$ th percent & 17 & 6 & 975 & 50 & $73.9 \%$ & $95.1 \%$ & $25.4 \%$ & $99.4 \%$ \\
\hline \multicolumn{9}{|l|}{73 - 96 hours } \\
\hline$<50$ th percent & 7 & 0 & 322 & 145 & $100 \%$ & $69.0 \%$ & $4.6 \%$ & $100 \%$ \\
\hline$<75$ th percent & 7 & 0 & 409 & 58 & $100 \%$ & $87.6 \%$ & $10.8 \%$ & $100 \%$ \\
\hline$<90$ th percent & 6 & 1 & 446 & 21 & $85.7 \%$ & $95.5 \%$ & $22.2 \%$ & $99.8 \%$ \\
\hline
\end{tabular}

conventional treatment to increase the skin's exposure (evidence level 1a) [37].

- Phototherapy should be discontinued once the bilirubin levels are below the threshold value for treatment on two consecutive measurements, 6-12 $\mathrm{h}$ apart. This would avoid keeping babies under phototherapy longer than necessary [38] (evidence level 1b).

- Serum bilirubin should be checked 12-24 hours after discontinuation of phototherapy the occurrence of post-phototherapy bilirubin rebound [39] (evidence level 4).

- Infants with either Rhesus or ABO haemolytic disease should be immediately treated with phototherapy once the diagnosis is made.
Hydration status should be monitored during phototherapy by daily weighing of the baby, assessing wept nappies and, if required, monitoring electrolytaemia. Breastfeeding should not be discontinued, because its interruption is associated with an increased frequency of stopping breastfeeding by one month (evidence level 2b) [40]. Italian Society of Neonatology suggests brief suspensions (up to 30 minutes) of phototherapy for allowing breastfeeding.

Breastfed babies should not be routinely supplemented with formula, water or dextrose water for the treatment of jaundice (evidence level $1 \mathrm{~b}$ ) $[7,41]$. The need for additional fluids during phototherapy should be considered only when the daily weight loss is higher then $5 \%$, or when breast milk is not sufficient to permit the full feeding.

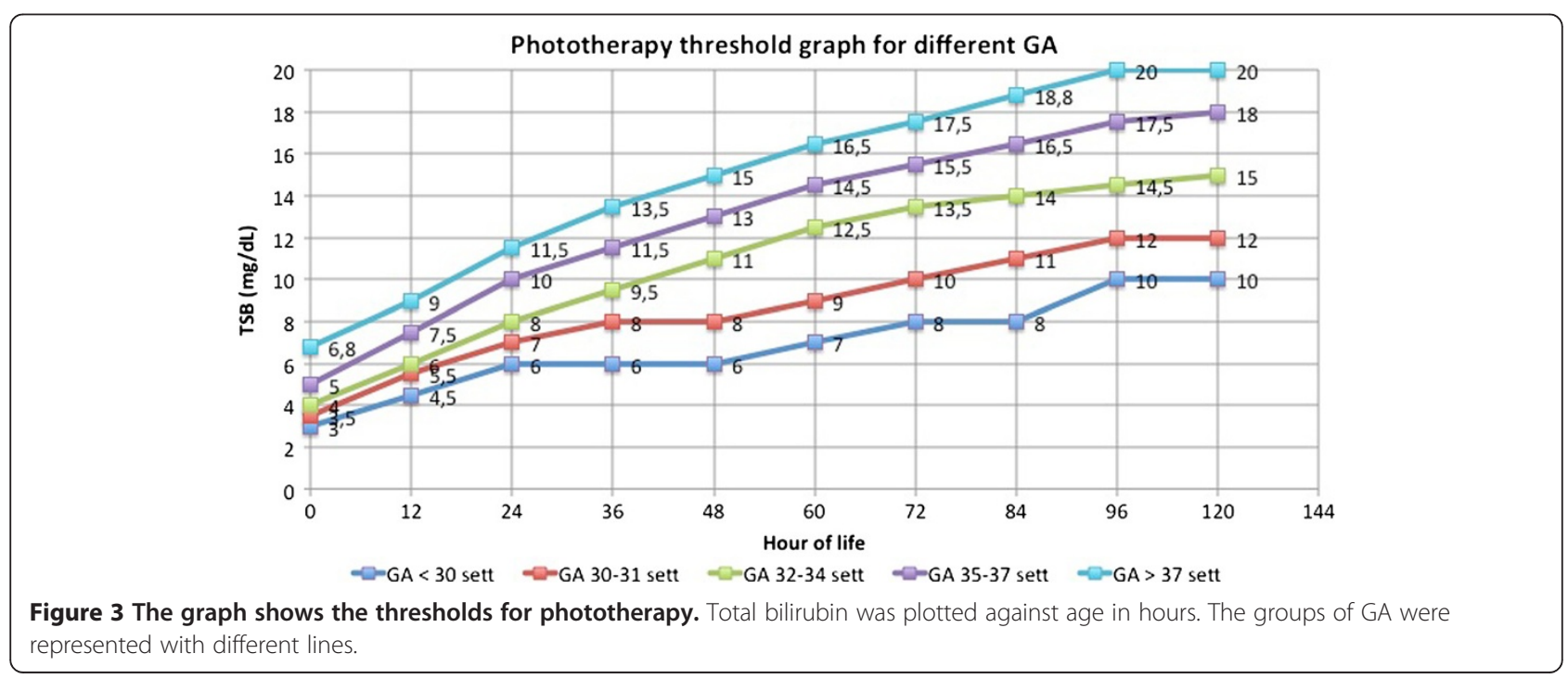




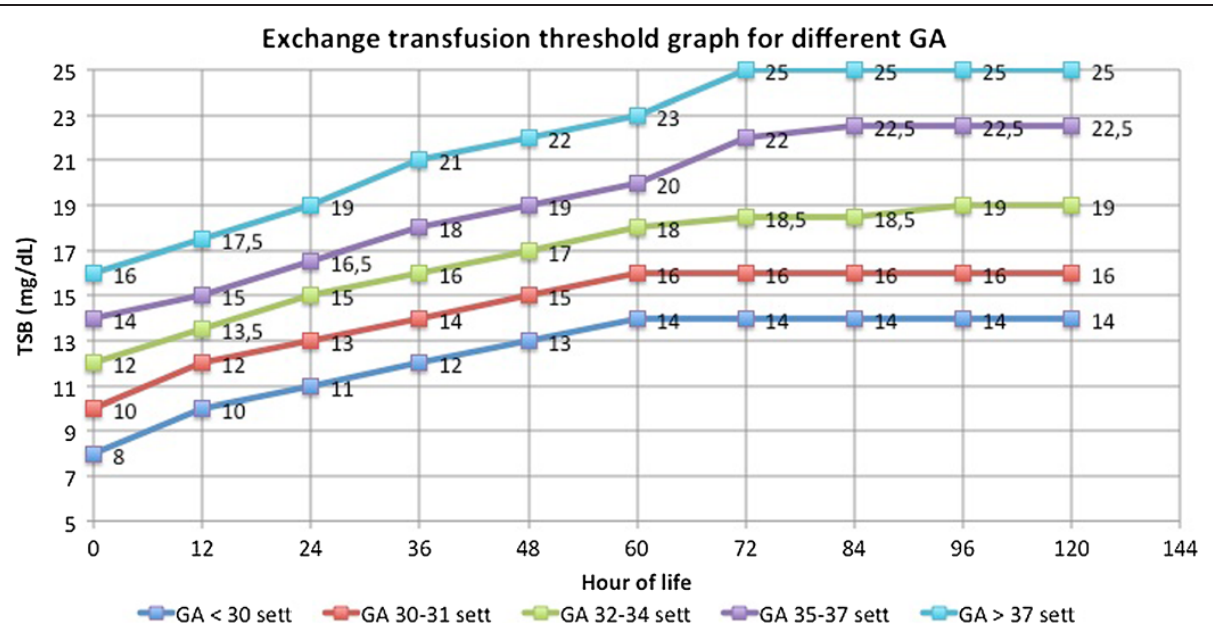

Figure 4 The graph shows the thresholds for exchange transfusion. Total bilirubin was plotted against age in hours. The groups of GA were represented with different lines.

\section{Exchange transfusion (ET)}

Exchange Transfusion is recommended for newborn infants with TSB levels at risk of neurologic damage and with clinical signs and symptoms of ABE. However, available guidelines suggest different thresholds for ET, without differences between haemolytic and non haemolytic jaundice.

TSB threshold for ET in newborns with non haemolytic jaundice are generally 5-6 mg/dL higher than TSB threshold for phototherapy (Figure 4).

The TSB threshold for ET in newborns with $\mathrm{Rh}$ or ABO haemolytic jaundice is lower than that of newborns with non haemolytic jaundice (Figure 5).

The more conservative approach to the treatment of $\mathrm{ABO}$ haemolytic disease compared to $\mathrm{Rh}$ haemolytic disease is due to its less aggressive development.

\section{Recommendations (see Additional file 1):}

- ET should be performed only by trained personnel in a neonatal intensive care unit with fully monitoring and resuscitation capabilities.

- Heart rate, breath rate, $\mathrm{SpO}_{2}$ and body temperature should be monitored during ET and for 12-24 hours after the end of the procedure.

- The most common adverse effects of ET are thrombocytopenia, haemolysis, hypocalcaemia, hypotension, venous thrombosis, hypokalaemia and hypoglycaemia and should be carefully monitored.

- Measurement of TSB should be performed before ET and at the end of the procedure.

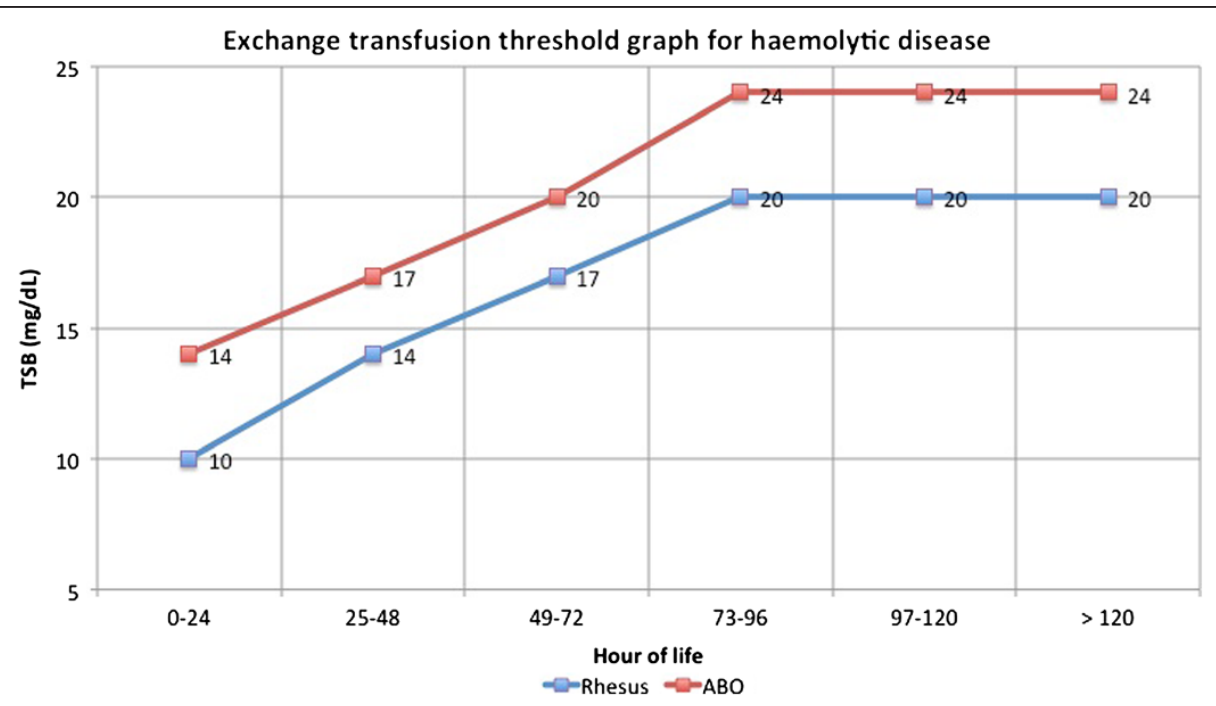

Figure 5 The graph shows the thresholds for exchange transfusion in case of haemolytic disease. Total bilirubin was plotted against age in hours. 
- As bilirubin levels may continue to rise after an ET we recommend that TSB is measured every 46 hours, and that phototherapy is continued.

- It is recommended to discontinue enteral feeding during ET and for 6 hours from the end of the procedure (evidence level 5).

- Infants underwent ET should be followed up for the development of anaemia after discharge.

\section{Other therapies}

Intravenous immunoglobulins (IVIG) act by preventing haemolysis. IVIG contain pooled IgG immunoglobulins extracted from the plasma of over 1000 blood donors. IVIG at a dose of either $500 \mathrm{mg} / \mathrm{kg}$ or 1 $\mathrm{gr} / \mathrm{kg}$ over $2-4$ hours reduce TSB in newborn infants with immune haemolytic jaundice $[42,43]$ and reduce the need for ET (evidence level 1a). IVIG should be administered in the first hours of life to infants with Rhesus haemolytic disease or ABO haemolytic disease when the serum bilirubin continues to rise by more than $0.5 \mathrm{mg} / \mathrm{dL}$ per hour.

\section{Italian registry of kernicterus and hyperbilirubinaemia} The Italian Society of Neonatology instituted the Italian Registry of Kernicterus and Hyperbilirubinaemia (RIKI: Registro Italiano del Kenicterus e dell'Iperbilirubinemia) for monitoring the incidence of kernicterus and severe hyperbilirubinaemia (TSB $>20 \mathrm{mg} / \mathrm{dL}$ or need for ET) in Italy. Each new case can be reported through the website of the Italian Society of Neonatology (www.neonatologia.it). The objective of this registry is to provide evidences of the guidelines effectiveness through the evaluation of severe hyperbilirubinaemia and kernicterus rate.

\section{Conclusion}

The development of national guidelines provide standardisation of the management of neonatal jaundice. Severe hyperbilirubinaemia in both healthy term or preterm newborn infants continues to carry the potential for complications from $\mathrm{ABE}$. The careful assessment of involved risk factors and the systematic approach to the management of hyperbilirubinaemia are essential to decrease the occurrence of kernicterus.

\section{Additional file}

\section{Additional file 1: Exchange transfusion procedure.}

\section{Abbreviations}

ABE: Acute bilirubin encephalopathy; B/A: Bilirubin/albumin ratio; ET: Exchange transfusion; GA: Gestational age; IVIG: Intravenous immunoglobulin; RBCs: Red blood cells; TSB: Total serum bilirubin; TCB: Transcutaneous bilirubin.

\section{Competing interests}

The authors declare that they have no competing interests.

\section{Authors' contributions}

CR, CD e FR conceived this study as Task Force for hyperbilirubinaemia of Italian Society of Neonatology. EZ, SP and LC revised literature and collected data from Italian studies. CR, GB and EZ conducted the study on transcutaneous bilirubin and serum bilirubin as predictors of severe hyperbilirubinaemia. GB and CR prepared the draft of the paper. CD, FR and SP made critical revision of the article. All authors read and approved the final manuscript.

\section{Author details}

${ }^{1}$ Division of Neonatology, Department of Pediatrics, Catholic University S H, Largo A. Gemelli, 8, Rome 00168, Italy. ${ }^{2}$ Section of Neonatology, Department of Surgical and Medical Critical Care, Careggi University, Hospital of Florence, Florence, Italy. ${ }^{3}$ Department of Pediatrics, Federico II University of Naples,

Corso Umberto I, 40, Napoli 80138, Italy.

Received: 27 January 2014 Accepted: 27 January 2014

Published: 31 January 2014

\section{References}

1. Maisels MJ, Kring E: Length of stay, jaundice, and hospital readmission. Pediatrics 1998, 101:995-998.

2. Friedman MA, Spitzer AR: Discharge criteria for the term newborn. Pediatr Clin North Am 2004, 51:599-618. viii.

3. Mercier CE, Barry SE, Paul K, Delaney TV, Horbar JD, Wasserman RC, Berry P, Shaw JS: Improving newborn preventive services at the birth hospitalization: a collaborative, hospital-based quality-improvement project. Pediatrics 2007, 120:481-488.

4. Lee KS, Perlman M, Ballantyne M, Elliott I, To T: Association between duration of neonatal hospital stay and readmission rate. J Pediatr 1995, 127:758-766.

5. Seidman DS, Stevenson DK, Ergaz Z, Gale R: Hospital readmission due to neonatal hyperbilirubinemia. Pediatrics 1995, 96:727-729.

6. Dani C, Poggi C, Barp J, Romagnoli C, Buonocore G: Current Italian practices regarding the management of hyperbilirubinaemia in preterm infants. Acta Paediatr 2011, 100:666-669.

7. American Academy of Pediatrics Subcommittee on $\mathrm{H}$ : Management of hyperbilirubinemia in the newborn infant 35 or more weeks of gestation. Pediatrics 2004, 114:297-316.

8. Maisels MJ, Bhutani VK, Bogen D, Newman TB, Stark AR, Watchko JF: Hyperbilirubinemia in the newborn infant > or $=35$ weeks' gestation: an update with clarifications. Pediatrics 2009, 124:1193-1198.

9. Bhutani VK, Committee on F, Newborn, American Academy of P: Phototherapy to prevent severe neonatal hyperbilirubinemia in the newborn infant 35 or more weeks of gestation. Pediatrics 2011, 128:e1046-e1052.

10. National Institute of Child Health and Clinical Excellence; 2011 http://pathways.nice.org.uk/pathways/neonatal-jaundice.

11. Atkinson M, Budge $\mathrm{H}$ : Review of the NICE guidance on neonatal jaundice. Arch Dis Child Educ Pract Ed 2011, 96:136-140.

12. Newman J: Guidelines for detection, management and prevention of hyperbilirubinemia in term and late preterm newborn infants (35 or more weeks' gestation) - Summary. Paediatr Child Health 2007, 12:401-418.

13. van Imhoff DE, Dijk PH, Hulzebos CV, Bartrial study group NNRN: Uniform treatment thresholds for hyperbilirubinemia in preterm infants: background and synopsis of a national guideline. Early Hum Dev 2011, 87:521-525

14. Bratlid D, Nakstad B, Hansen TW: National guidelines for treatment of jaundice in the newborn. Acta Paediatr 2011, 100:499-505

15. Kaplan M, Merlob P, Regev R: Israel guidelines for the management of neonatal hyperbilirubinemia and prevention of kernicterus. J Perinatol 2008, 28:389-397.

16. Newborn Service Clinical Guideline: Management of Neonatal Jaundice http://www.adhb.govt.nz/newborn/guidelines/Gl/Jaundice.htm.

17. Queensland Maternity and Neonatal Clinical Guideline: Neonatal Jaundice: Prevention, Assessment and Management; 2009. http://www.health.qld.gov. au/qcg/.

18. Mishra S, Agarwal R, Deorari AK, Paul VK: Jaundice in the Newborn. AlIMS-NICU Protocols; 2007. http://www.newbornwhocc.org/.

19. Association Espanola de Pediatria, Rodriguez Miguelez JM, Figueras Aloy J: Ictericia Neonatal. http://www.aeped.es/documentos/protocolos-neonatologia. 
20. Arlettaz R, Blumberg A, Buetti L, Fahnenstich H, Mieth D, Roth-Kleiner M: Assessment and treatment of jaundice newborn infants 35 0/7 or more weeks of gestation. Swiss Soc Neonatology 2007:1-4. http://www.neonet. ch/assets/pdf/2006_Bili-Empfehlungen_e_final.pdf.

21. De Luca D, Romagnoli C, Tiberi E, Zuppa AA, Zecca E: Skin bilirubin nomogram for the first $96 \mathrm{~h}$ of life in a European normal healthy newborn population, obtained with multiwavelength transcutaneous bilirubinometry. Acta Paediatr 2008, 97:146-150.

22. Romagnoli C, Tiberi E, Barone G, De Curtis M, Regoli D, Paolillo P, Picone S, Anania S, Finocchi M, Cardiello V, Zecca E: Validation of transcutaneous bilirubin nomogram in identifying neonates not at risk of hyperbilirubinaemia: a prospective, observational, multicenter study. Early Hum Dev 2012, 88:51-55.

23. Romagnoli C, Tiberi E, Barone G, Curtis MD, Regoli D, Paolillo P, Picone S, Anania S, Finocchi M, Cardiello V, Giordano L, Paolucci V, Zecca E: Development and validation of serum bilirubin nomogram to predict the absence of risk for severe hyperbilirubinaemia before discharge: a prospective, multicenter study. Ital J Pediatr 2012, 38:6.

24. Oxford Centre for Evidence-Based Medicine. http://www.cebm.net/?o=1025.

25. Maisels MJ, Watchko JF: Treatment of jaundice in low birthweight infants. Arch Dis Child Fetal Neonatal Ed 2003, 88(6):F459-F463.

26. Watchko JF, Maisels MJ: Jaundice in low birthweight infants: pathobiology and outcome. Arch Dis Child Fetal Neonatal Ed 2003, 88(6):F455-F458.

27. Moyer VA, Ahn C, Sneed S: Accuracy of clinical judgment in neonatal jaundice. Arch Pediatr Adolesc Med 2000, 154:391-394.

28. De Luca D, Zecca E, Zuppa AA, Romagnoli C: The joint use of human and electronic eye: visual assessment of jaundice and transcutaneous bilirubinometry. Turk J Pediatr 2008, 50:456-461.

29. Riskin A, Tamir A, Kugelman A, Hemo M, Bader D: Is visual assessment of jaundice reliable as a screening tool to detect significant neonatal hyperbilirubinemia? J Pediatr 2008, 152:782-787. 787 e781-782.

30. Knudsen $\mathrm{A}$ : The influence of the reserve albumin concentration and $\mathrm{pH}$ on the cephalocaudal progression of jaundice in newborns. Early Hum Dev 1991, 25:37-41.

31. Knudsen A, Brodersen R: Skin colour and bilirubin in neonates. Arch Dis Child 1989, 64:605-609.

32. Romagnoli C, Catenazzi P, Barone G, Giordano L, Riccardi R, Zuppa AA, Zecca E: BiliCheck vs JM-103 in identifying neonates not at risk of hyperbilirubinaemia. Ital J Pediatr 2013, 39:46.

33. Romagnoli C, Zecca E, Catenazzi P, Barone G, Zuppa AA: Transcutaneous bilirubin measurement: comparison of Respironics BiliCheck and JM-103 in a normal newborn population. Clin Biochem 2012, 45:659-662.

34. Bhutani VK, Johnson L, Sivieri EM: Predictive ability of a predischarge hour-specific serum bilirubin for subsequent significant hyperbilirubinemia in healthy term and near-term newborns. Pediatrics 1999, 103:6-14.

35. Yu ZB, Dong XY, Han SP, Chen YL, Qiu YF, Sha L, Sun Q, Guo XR: Transcutaneous bilirubin nomogram for predicting neonatal hyperbilirubinemia in healthy term and late-preterm Chinese infants. Eur J Pediatr 2011, 170:185-191.

36. Varvarigou A, Fouzas S, Skylogianni E, Mantagou L, Bougioukou D, Mantagos S: Transcutaneous bilirubin nomogram for prediction of significant neonatal hyperbilirubinemia. Pediatrics 2009 , 124:1052-1059

37. Mills JF, Tudehope D: Fibreoptic phototherapy for neonatal jaundice. Cochrane Database Syst Rev 2001, 1:CD002060.

38. Barak M, Berger I, Dollberg S, Mimouni FB, Mandel D: When should phototherapy be stopped? A pilot study comparing two targets of serum bilirubin concentration. Acta Paediatr 2009, 98:277-281.

39. Kaplan M, Kaplan E, Hammerman C, Algur N, Bromiker R, Schimmel MS, Eidelman Al: Post-phototherapy neonatal bilirubin rebound: a potential cause of significant hyperbilirubinaemia. Arch Dis Child 2006, 91:31-34

40. Kemper K, Forsyth B, McCarthy P: Jaundice, terminating breast-feeding, and the vulnerable child. Pediatrics 1989, 84:773-778.

41. Martinez JC, Maisels MJ, Otheguy L, Garcia H, Savorani M, Mogni B, Martinez JC Jr: Hyperbilirubinemia in the breast-fed newborn: a controlled trial of four interventions. Pediatrics 1993, 91:470-473.
42. Alcock GS, Liley H: Immunoglobulin infusion for isoimmune haemolytic jaundice in neonates. Cochrane Database Syst Rev 2002, 3:CD003313.

43. Miqdad AM, Abdelbasit OB, Shaheed MM, Seidahmed MZ, Abomelha AM, Arcala OP: Intravenous immunoglobulin G (IVIG) therapy for significant hyperbilirubinemia in $\mathrm{ABO}$ hemolytic disease of the newborn. $J$ Matern Fetal Neonatal Med 2004, 16:163-166.

doi:10.1186/1824-7288-40-11

Cite this article as: Romagnoli et al:: Italian guidelines for management and treatment of hyperbilirubinaemia of newborn infants $\geq 35$ weeks' gestational age. Italian Journal of Pediatrics 2014 40:11.

\section{Submit your next manuscript to BioMed Central and take full advantage of:}

- Convenient online submission

- Thorough peer review

- No space constraints or color figure charges

- Immediate publication on acceptance

- Inclusion in PubMed, CAS, Scopus and Google Scholar

- Research which is freely available for redistribution

Submit your manuscript at www.biomedcentral.com/submit
C) BioMed Central 